\title{
Influence of increased adrenergic activity and magnesium depletion on cardiac rhythm in alcohol withdrawal
}

\author{
Hans Denison, Sverker Jern, Rudolf Jagenburg, Christer Wendestam, Sven Wallerstedt
}

\begin{abstract}
Objective-To investigate the prevalence of arrhythmias in alcoholic men during detoxification and its relation to neuroendocrine activation and electrolyte disturbances.
\end{abstract}

Design-Consecutive case-control study. Setting-Primary and secondary care, detoxification ward.

Patients and controls-19 otherwise healthy alcoholic men (DSM-III-R) with withdrawal symptoms necessitating detoxification in hospital. 19 age matched, healthy non-alcoholic men as controls for Holter recordings.

Interventions-Treatment with chlomethiazole; additional treatment with carbamazepine in patients with previous seizures.

Main outcome measures-Computer based analyses of mean heart rate and arrhythmias from 24 hour Holter recordings, 24 hour urinary excretion of adrenaline and noradrenaline, magnesium retention measured by means of intravenous loading test, and serum concentrations of electrolytes.

Results-The 24 hour mean heart rate was higher in the alcoholic men (97.4 beats/minute, $95 \%$ confidence interval (CI) 91.2 to 103.6 ) than in the controls (69.6 beats/minute, $95 \%$ CI 65.4 to $73.8, P$ $<0.001$ ). However, there was no difference in diurnal heart rate variation. The prevalence of premature supraventricular depolarisations was lower in the alcoholic men $(P<0.05)$. Neither atrial fibrillation nor malignant ventricular arrhythmias occurred. The sinus tachycardia in the alcoholic men correlated with the concomitant urinary excretion of catecholamines $(P<0.05)$. The mean serum magnesium concentration was $0.78 \mathrm{mmol} / \mathrm{l}(95 \% \mathrm{CI} 0.73$ to 0.83$)$ in the alcoholic men and $0.83 \mathrm{mmol} / \mathrm{l}(95 \% \mathrm{CI}$ 0.81 to 0.85 ) in a reference population of 55 men aged 40. Magnesium depletion (defined as magnesium retention $>\mathbf{3 0} \%$ ) was detected in 10 alcoholic men (53\%). Three alcoholic men had serum potassium concentrations $\leqslant 3.3 \mathrm{mmol} / \mathrm{l}$ on admission.

Conclusion-Increased adrenergic activity, magnesium depletion, and hypokalaemia are often seen after heavy drinking, but in alcoholic men without clinical heart disease these changes were not accompanied by arrhythmias other than sinus tachycardia during detoxification in hospital.

(Br Heart f 1994;72:554-560)

Among middle aged men misuse of alcohol is a major contributor to death. ${ }^{1}$ Sudden, unwitnessed death is common in alcoholics. ${ }^{2}$ Even after medicolegal examination the causes of death remain obscure in $10-20 \%$ of those who misuse alcohol. ${ }^{34}$ In such cases the blood concentration of ethanol is usually zero or very low, ${ }^{4}$ suggesting that death may have occurred during alcohol withdrawal. It is likely that arrhythmias cause most of these deaths, but there are few studies on arrhythmias in alcoholics after heavy drinking.

We postulated that neuroendocrine activation and electrolyte disturbances accompanying alcohol abuse are involved in the pathogenesis of sudden death in alcoholic patients. The hyperadrenergic state seen during alcohol withdrawal ${ }^{5}$ could make the myocardium more susceptible to arrhythmias. In addition, magnesium deficiency, which is common in alcoholics, ${ }^{67}$ is associated with malignant ventricular arrhythmias ${ }^{8}$ though more recently it has been proposed that the arrhythmias described in magnesium depleted patients may be induced by concomitant hypokalaemia. ${ }^{910}$

The present study was designed to investigate the prevalence of cardiac arrhythmias in alcoholic men during detoxification in hospital and to explore possible relations between arrhythmias, increased adrenergic activity, and magnesium depletion. To examine the specific effect of alcohol abuse on cardiac rhythm we studied patients without heart disease or other conditions associated with arrhythmia.

\section{Patients and methods}

PATIENTS

One of us (HD) considered the eligibility of $\overline{0}$ all men admitted to a detoxification ward at 8 Lillhagen Hospital (Gothenburg, Sweden) 을 between September 1, 1989, and March 1, 흘 1990. This unit served a catchment area of about 42000 men aged $\geqslant 20$ years, and about 400 patients aged $\leqslant 60$ years were treated as inpatients each year. 
had:

- A diagnosis (DSM-III-R) of alcohol dependence

- A reported daily ethanol ingestion of $\geqslant 120 \mathrm{~g}$ for at least one week

- Withdrawal symptoms necessitating treatment in hospital.

In addition, investigations had to start within 72 hours of the last drinking bout.

Patients with the following characteristics were excluded

- Age $>60$ years

- Symptoms or signs of heart disease

- Treatment for hypertension

- Renal disease (serum creatinine >130 $\mu \mathrm{mol} / \mathrm{l})$

- Diabetes mellitus (fasting blood glucose $>7.0 \mathrm{mmol} / \mathrm{l}$ )

- Treatment with diuretics or other drugs that could interfere with electrolyte balance and heart rhythm

- Abuse of narcotics and benzodiazepines

- Delirium tremens and other major psychiatric disorders making cooperation difficult.

In addition, because of limited access to laboratory facilities, patients could only be included 4 days a week.

Nineteen of 25 eligible patients gave their written, informed consent to participate in the study, which was approved by the Research Ethics Committee, University of Gothenburg.

A urine specimen was collected at entry to the study and screened for metabolites of benzodiazepines, cannabis, amphetamine, and opiates. All tests were negative in 16 of the 19 patients. Three men had positive benzodiazepine tests; one had been given benzodiazepines during an attempt at outpatient detoxification the week before admission, one

Table 1 Age, body mass index, and alcohol history in 19 alcoholic men

\begin{tabular}{lc}
\hline Variable & Median (Range) \\
\hline Age $(\mathrm{yr})$ & $45(34-55)$ \\
$\mathrm{BMI}\left(\mathrm{kg} / \mathrm{m}^{2}\right)$ & $22 \cdot 9(20 \cdot 3-27 \cdot 4)$ \\
Time with diagnosis of alcoholism (yr) & $15(4-30)$ \\
Number of admissions for detoxification & $3(1-12)$ \\
during past 12 months & $19(7-74)$ \\
Duration of last drinking bout & $($ days) \\
Reported daily amount of ethanol & $240(120-480)$ \\
ingested during last bout $(\mathrm{g})$ & \\
\hline
\end{tabular}

*Valid reports available for 16 patients. BMI, body mass index.

Table 2 Haematological and biochemical variables on the day after admission in 19 alcoholic men treated on a detoxification ward

\begin{tabular}{llll}
\hline Variables & Reference interval & Median value & Range \\
\hline B-Hb & $132-166 \mathrm{~g} / 1$ & 139 & $105-158$ \\
Ery-MCV & $78-102 \mathrm{fl}$ & 95 & $64-110$ \\
S-ASAT & $<0 \cdot 7 \mu \mathrm{kat} / 1$ & $1 \cdot 0$ & $0 \cdot 36-10$ \\
S-ALAT & $<0 \cdot 7 \mu \mathrm{kat} / 1$ & $0 \cdot 76$ & $0 \cdot 21-8 \cdot 5$ \\
S-GGT & $<1 \cdot 0 \mu \mathrm{kat} / 1$ & $0 \cdot 72$ & $0 \cdot 34-51^{\star}$ \\
S-albumin & $36-50 \mathrm{~g} / 1$ & 41 & $33-46$ \\
S-creatinine & $60-120 \mu \mathrm{mol} / 1$ & 85 & $68-128$ \\
S-CDT & $<20 \mathrm{U} / 1$ & $32 \cdot 6$ & $16 \cdot 7-107 \dagger$ \\
B-glucose & $3 \cdot 9-5 \cdot 8 \mathrm{mmol} / 1$ & $4 \cdot 7$ & $2 \cdot 5-7 \cdot 2 \ddagger$ \\
P-(factor II-VII-X) & $70-130 \%$ & 130 & $80-185$ \\
\hline
\end{tabular}

B-Hb, blood haemoglobin; Ery-MCV, erythrocyte mean corpuscular volume; S-ASAT, serum aspartate aminotransferase; S-ALAT, serum alanine aminotransferase; S-GGT, serum gamma glutamyl transferase; S-CDT, serum carbohydrate deficient transferrin; P-II-VII-X, plasma coagulation factors.

^Second highest value $8 \cdot 2 \mu \mathrm{kat} / \mathrm{l}$.

$+\mathrm{N}=18$, one missing specimen.

fOne patient had a fasting B-glucose concentration $>7.0 \mathrm{mmol} / \mathrm{l}$

On the next day the concentration was $6.5 \mathrm{mmol} / \mathrm{l}$. had been prescribed benzodiazepines in small amounts for temporary sleeping problems, and the third patient was not aware of having ingested any benzodiazepines. Because none of these patients was known to abuse these drugs they were not excluded.

We collected data on social situation, smoking habits, drug and alcohol history, and the amounts and duration of recent alcohol consumption (table 1).

Eleven patients had regular employment; the rest were supported by the social welfare system. All were smokers; 16 patients consumed more than 20 cigarettes per day. Ten of the 19 alcoholic men had had confirmed delirium tremens and eight had had withdrawal seizures.

\section{TREATMENT}

After admission, the patients were treated according to the routines in the detoxification ward with chlomethiazole, $600 \mathrm{mg}$ by mouth four times a day for the first days. If necessary the dose of chlomethiazole was increased to control withdrawal symptoms and keep the heart rate below 100 beats/minute. The mean (SD) amount of chlomethiazole given during the Holter recordings was $2.9(0.8) \mathrm{g}$ (range $0 \cdot 6-4 \cdot 1)$. Carbamazepine (200 $\mathrm{mg}$ by mouth three times a day) was given to the eight patients with a history of withdrawal seizures and to three further patients. All patients were given vitamin B complex with high doses of thiamine by mouth or intramuscularly, depending on their nutritional state. If necessary propiomazine $(50 \mathrm{mg})$ or alimemazine (20-40 mg) was given.

\section{STUDY DESIGN}

A 24 hour Holter recording was started on the morning after admission, at a median 36 hours after the last drinking bout (range 24-72 h). We started a 24 hour urine collection for analysis of catecholamine excretion at the same time. The next morning we started an intravenous magnesium infusion and another 24 hour urine collection for analysis of magnesium. We drew blood samples for haematological and biochemical analyses before breakfast the day after admission (table 2) and for the next two days.

\section{CONTROL GROUP}

A control group of 19 age matched healthy male students, physicians, and teachers was recruited for 24 hour Holter recordings, performed while they were carrying out their usual daily activities.

\section{BIOCHEMICAL METHODS}

We measured urinary concentrations of noradrenaline and adrenaline by high performance liquid chromatography with electrochemical detection. We measured blood haemoglobin (B-Hb) and erythrocyte mean corpuscular volume (Ery-MCV) by the Technicon H1 system, serum aspartate aminotransferase (EC 2.6.1.1, S-ASAT) and alanine aminotransferase (EC 2.6.1.2, S-ALAT) by the methods proposed by the Committee on 
Enzymes of the Scandinavian Society for Clinical Chemistry, ${ }^{11}$ serum $\gamma$-glutamyl transferase (EC 2.3.2.2, S-GGT) by the Szasz method (Granutest 100, Merck Diagnostica), serum potassium (S-K) by flame photometry, serum and urinary magnesium ( $\mathrm{S}-\mathrm{Mg}$, tU$\mathrm{Mg}$ ) by atomic absorption spectrometry (Perkin Elmer model 403), serum albumin (S-albumin) by a dye binding method (bromocresol green), serum creatinine (Screatinine) by an alkaline picrate method, blood glucose (B-Glucose) by a glucose dehydrogenase method, plasma bicarbonate (P-Bic standard) with a blood gas analyser (ABL 500, Radiometer), and serum carbohydrate deficient transferrin (S-CDT) by ionexchange chromatography followed by radioimmunological assay (CDTect, Kabi Pharmacia Diagnostics). The enzymes, albumin, creatinine, and glucose were measured by a Greiner G450 analyser. Blood ethanol was determined with gas chromatography (glass column with $1.5 \%$ Carbowax on Carbopak B with $\mathrm{n}$-propanol as internal standard). The coagulation factors II-VII-X (citrate plasma) were determined using reagents from Diagnostica Stago (Prothrombin Assay SPA 50).

The reference intervals stated are those of the laboratory, except for serum magnesium where frozen specimens from the alcoholic men and a reference population of 55 healthy men aged 40 were analysed in the same assay run.

We used commercial immunological techniques (TDx Abbott) to screen for drug metabolites in urine. Detection concentrations were $100 \mu \mathrm{g} / 1$ (nordiazepam) for benzodiazepines, $0.5 \mathrm{mg} / \mathrm{l}$ (d,l-amphetamine) for the amphetamines, $20 \mu \mathrm{g} / 1$ (11-nor-delta-9tetrahydrocannabinol-9-COOH) for cannabinoids, and $200 \mathrm{mg} / \mathrm{l}$ (morphine) for opiates were regarded as negative. Positive tests were confirmed by an independent chromatographic method.

INTRAVENOUS MAGNESIUM LOADING TEST An intravenous infusion of magnesium sulphate (Addex-Magnesium, Kabi Pharmacia) (30 mmol) in $1000 \mathrm{ml}$ saline (Natriumklorid,

Figure 1 Heart rate (mean value, 95 percent confidence interval) during four 6 hour intervals calculated from Holter recordings in 19 alcoholic men during withdrawal and 19 age matched, healthy controls.
Kabi Pharmacia) was given over 8 hours. Meanwhile, the patients were allowed to eat the regular hospital food. We measured magnesium excretion in the 24 hour urine collection after the start of the magnesium infusion. The magnesium retention was calculated as the difference between the amount of magnesium infused $(30 \mathrm{mmol})$ and the amount excreted. Magnesium retention of $>30 \%$ was regarded as evidence of a deficiency.

HOLTER RECORDINGS

The 24 hour electrocardiographic recordings (Holter recordings) were obtained on TDK D-90N tapes by a Tracker TR1 (Reynolds Medical, Hertford) with a V1 and V5-like electrode position, replayed on a Pathfinder 2 (Reynolds Medical) and computer analysed. The evaluable registration time was $\geqslant 2300$ in 17 of the alcoholic men and 18 in the controls (range 2033-2358 and 2255-2359).

\section{ECG REGISTRATIONS}

On one of the first days we obtained a resting 12 lead routine electrocardiogram (ECG) in all except one of the patients (Siemens Mingograph 740, Siemens Elema, Stockholm). The ECGs were classified according to the Minnesota code. ${ }^{12}$

The QT interval (QT) was measured by two independent observers on V5 baseline ECG complexes averaged over one minute from Holter recordings at a paper speed of 50 $\mathrm{mm} / \mathrm{s}$. The interobserver coefficient of variation for QT-interval measurement was $2 \cdot 2 \%$ (standard deviation for the mean difference between observers divided by mean QT time for all 38 measurements). The corrected QT interval $\left(\mathrm{QT}_{\mathrm{c}}\right)$ was calculated from the mean value of the two QT interval measurements for each subject according to Hodges' linear formula:

$$
\begin{aligned}
& \mathrm{QT}_{\mathrm{c}}= \\
& \mathrm{QT}+\frac{1 \cdot 75^{\star}(\text { heart rate }-60)}{1000} \text { seconds. }^{13}
\end{aligned}
$$

STATISTICAL ANALYSIS

Mean heart rate, $\mathrm{QT}_{\mathrm{c}}$, and electrolyte concen- $\frac{\mathrm{T}}{\mathrm{O}}$ trations are presented as mean values with $95 \%$ confidence intervals $(95 \% \mathrm{CI})$ calculated $\sigma$ on the assumption of $t$ distribution. The val- $N$ ues for the other variables are given as median $\underset{\omega}{N}$ (range). We used two-tailed Student's $t$ tests for independent groups to compare the mean 0 heart rates of the alcoholic men and controls and Wilcoxon's signed ranks test for paired $\stackrel{\oplus}{?}$ comparison of the $\mathrm{QT}_{\mathrm{c}}$ time, the prevalence of $\frac{T}{0}$ premature supraventricular and ventricular $\underset{\mathbb{D}}{\stackrel{O}{*}}$ depolarisations in the alcoholic men and the $\frac{?}{8}$ age matched controls, and analysis of changes $\stackrel{2}{2}$ in serum electrolyte concentrations in the alcoholic group. Pearson's correlation coeffi- 8 cient was used to measure correlations? between variables. To calculate the correlation between mean heart rate and cate-? cholamine excretion in the alcoholic men we used $\log$ transformed catecholamine values, because these values were widely scattered. A $P$ value of $<0.05$ was regarded as statistically 


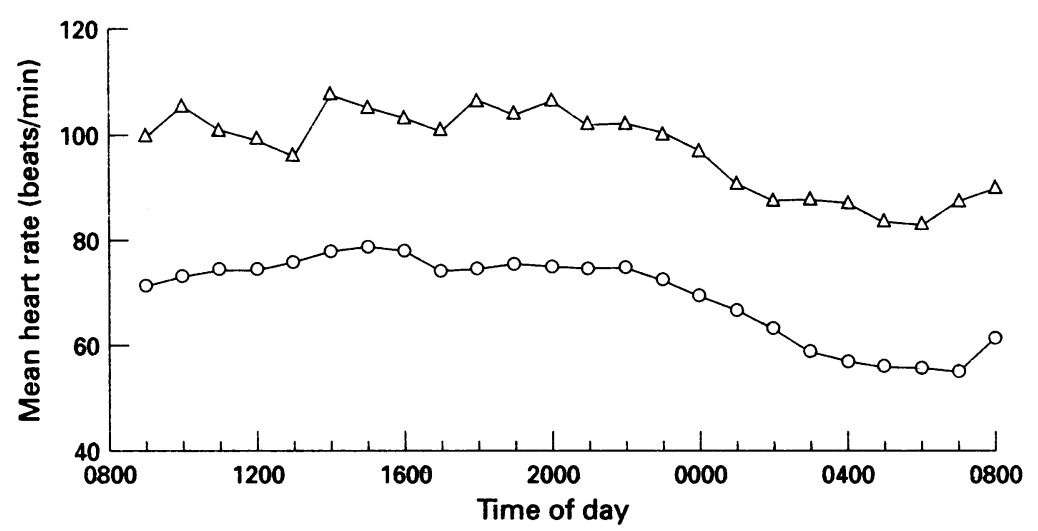

$\triangle$ Alcoholic men $-o$ Age matched controls

Figure 2 Diurnal heart rate variability in 19 alcoholic men during withdrawal and 19 controls, calculated from mean heart rates every hour from Holter recordings.

significant. We used Minitab 6.1 (Minitab, USA), Q \& A Graphstat, Version 1.0 (Symantec Corporation, USA), and Stat View II (Abacus Concepts, Berkeley, CA, USA) computer programs for the calculations.

\section{Results}

HOLTER ANALYSIS

The alcoholic men had a higher mean heart rate $(97.4$ beats/minute, $95 \%$ CI 91.2 to $103.6)$ than the controls $(69.6$ beats/minute, $95 \%$ CI 65.4 to 73.8 ; $\mathrm{P}<0.001$ for each 6 hour interval, fig 1). There was a similar diurnal variation in heart rate in the alcoholic and the control groups (fig 2). The mean heart rate in the study group correlated significantly with the excretion of catecholamines (fig 3).

Premature supraventricular depolarisations (PSVD) and premature ventricular depolarisations (PVD) were uncommon during the recordings in alcoholic men and controls (table 3). PSVD were significantly less prevalent in alcoholic men $(P<0.05)$, but the prevalence of PVD was similar in both groups. There were no episodes of atrial fibril-
Table 3 Prevalence of premature supraventricular depolarisations (PSVD) and premature ventricular depolarisations (PVD) during 24 hours of ambulatory electrocardiography in 19 alcoholic men in 19 age matched controls

\begin{tabular}{lrc}
\hline & $\begin{array}{l}\text { Alcoholics } \\
(n)\end{array}$ & $\begin{array}{l}\text { Controls } \\
(n)\end{array}$ \\
\hline $\begin{array}{l}\text { Number of PSVD/24h: } \\
0-10\end{array}$ & 16 & 10 \\
$11-20$ & 2 & 6 \\
$>20$ & 1 & 3 \\
Number of PVD/24h: & & \\
$0-10$ & 16 & 18 \\
$11-20$ & 1 & 0 \\
$>20$ & 2 & 1 \\
\hline
\end{tabular}

lation or malignant ventricular arrhythmias in either group.

\section{ECG EVALUATIONS}

According to the Minnesota code, the ECG of one patient was classified as indicating a possible previous myocardial infarction. Another ECG, classified as indicating probable previous myocardial infarction, showed intraventricular conduction disturbances, which were thought to explain the presence of numerous $Q$ waves on this ECG.

The mean value for $\mathrm{QT}_{\mathrm{c}}$ was $0.41 \mathrm{~s}(95 \%$ CI 0.40 to 0.42 ) in the alcoholic men and $0.40 \mathrm{~s}(95 \% \mathrm{CI} 0.39$ to 0.41$)$ in the controls $(P>0 \cdot 2)$. There were no significant correlations between $\mathrm{QT}_{\mathrm{c}}$ and serum magnesium concentrations $(r=0.14)$ or magnesium retention $(r=0.07)$ in the alcoholic men.

\section{BIOCHEMICAL STUDIES}

In 18 of the 19 patients no ethanol could be detected in serum in the morning the day after admission. In one patient the ethanol concentration was $21 \mathrm{mmol} / \mathrm{l}$.

The urine collection for the excretion of catecholamines was considered adequate in 18 of the patients. The median excretion of noradrenaline was $502 \mathrm{nmol} / 24$ hours (range 209-3100 nmol/24 hours). In seven (38\%) of the 18 evaluable patients excretion was higher than the reference limit of 560 $\mathrm{nmol} / 24 \mathrm{~h}$. The median value for excretion of adrenaline was $55 \mathrm{nmol} / 24 \mathrm{~h}$ (range 28-180
Figure 3 Interrelations between excretion of noradrenaline and adrenaline in $24 \mathrm{~h}$ urine samples and mean heart rate from concomitantly performed Holter recordings in 18 alcoholic men during detoxification in hospital.

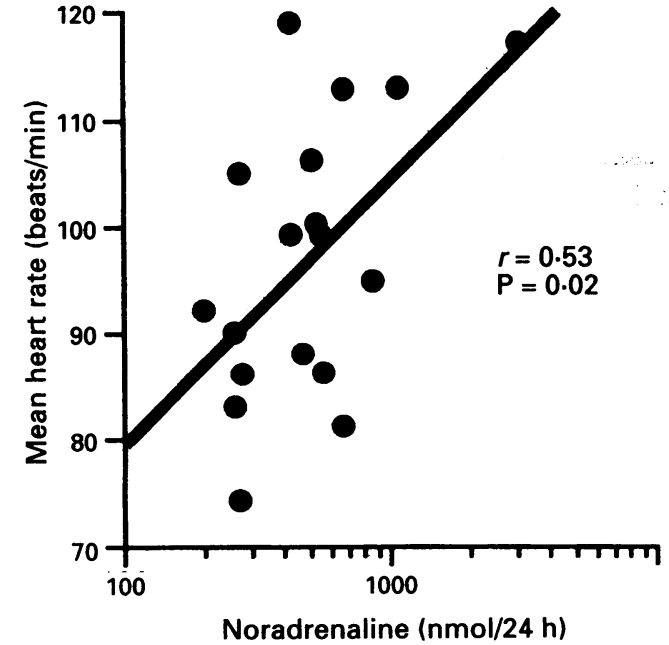

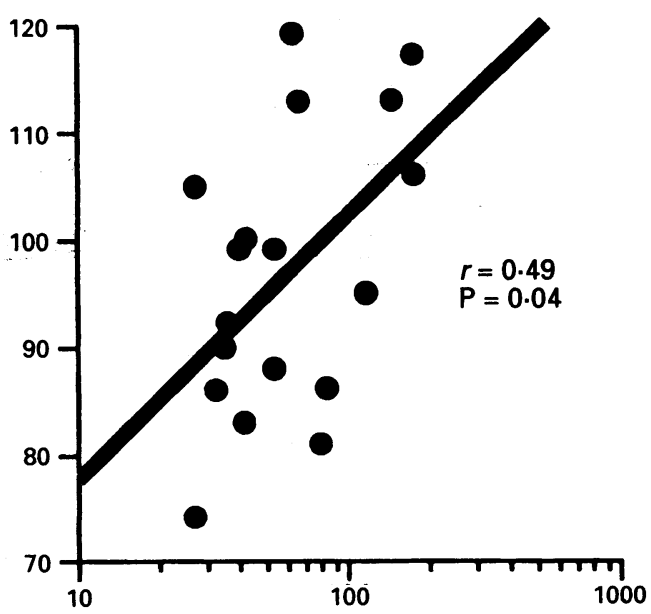

Adrenaline (nmol/24 h) 
Table 4 Concentrations of serum magnesium and potassium and plasma bicarbonate before and after intravenous magnesium infusion (30 mmol during 8 hours) in 19 alcoholic men during detoxification after heavy drinking (mean (SD)).

\begin{tabular}{|c|c|c|c|}
\hline & $\begin{array}{l}\mathrm{Mg} \\
(\mathrm{mmol} / \mathrm{l})\end{array}$ & $\begin{array}{l}\text { K } \\
(m m o l l l)\end{array}$ & $\begin{array}{l}\text { Bicarbonate } \\
\text { (mmolll) }\end{array}$ \\
\hline $\begin{array}{l}\text { Reference interval } \\
\text { Day before } \mathrm{Mg} \text { infusion } \\
\text { At start of } \mathrm{Mg} \text { infusion } \\
24 \text { hours after start }\end{array}$ & $\begin{array}{l}0.69-0.95^{\star} \\
0.78(0.09) \\
0.75(0.08)\end{array}$ & $\begin{array}{l}3.3-4.6 \\
3.81(0.52) \\
3.96(0.47)\end{array}$ & $\begin{array}{l}21-27 \\
26 \cdot 3(2 \cdot 9) \\
24 \cdot 2(3 \cdot 0)\end{array}$ \\
\hline of $\mathrm{Mg}$ infusion & $0 \cdot 89+(0 \cdot 12)$ & $4 \cdot 29+(0.54)$ & $23 \cdot 3+(1 \cdot 6)$ \\
\hline
\end{tabular}

$\star 95 \%$ central range of a reference group consisting of 55 healthy men aged 40 . $+\mathrm{P}<0.001$ significant change as compared with the day after admission.

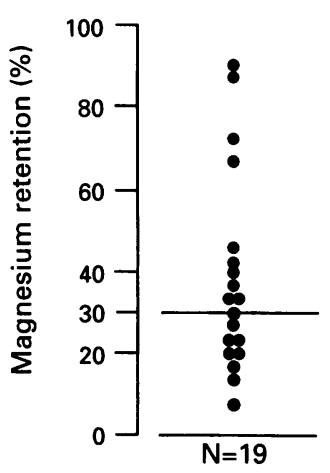

Figure 4 Retention of magnesium during 24 hours after start of an intravenous loading test with $30 \mathrm{mmol}$

magnesiumsulphate in 19 alcoholic men. Magnesium depletion was defined as retention of $30 \%$. $\mathrm{nmol} / 24 \mathrm{~h})$. In four (22\%) of the 18 alcoholic men adrenaline excretion was above the reference limit of $101 \mathrm{nmol} / 24 \mathrm{~h}$. There was a significant correlation between the excretion of noradrenaline and adrenaline $(r=0.71, \mathrm{P}<$ 0.001 ).

The mean serum magnesium concentration on admission tended to be lower in the alcoholic men $(0.78 \mathrm{mmol} / 1,95 \%$ CI 0.73 to $0.83)$ than in the reference group $(0.83$ $\mathrm{mmol} / \mathrm{l}, 95 \% \mathrm{CI} 0 \cdot 81$ to $0 \cdot 85)$. The day after the magnesium infusion, the mean serum magnesium concentration had increased significantly (table 4).

Magnesium retention was $>30 \%$ in 10 $(53 \%)$ of the 19 patients and $>50 \%$ in four (21\%) (fig 4$)$. There was no significant correlation between the serum magnesium concentration and the magnesium retention $(r=-0 \cdot 21)$.

On admission the serum potassium concentration was $\leqslant 3.3 \mathrm{mmol} / \mathrm{l}$ in three $(16 \%)$ of the 19 patients. The mean serum potassium concentration in the alcoholic group increased significantly during the treatment period, whereas the mean standard bicarbonate concentration declined (table 4).

\section{Discussion}

Since most alcoholic patients in whom cause of death is obscure die outside hospital it is difficult to devise methods to explore the pathogenesis of such deaths. We postulated that if lethal arrhythmias were involved in these cases, it might be possible to detect arrhythmias in alcoholic men during detoxification in hospital. Because no serious arrhythmias occurred in our patients we could not confirm our hypothesis. The alcoholic men had significantly fewer premature supraventricular depolarisations than the controls. This finding was of no clinical significance, however, because the prevalence of premature depolarisations was low in both groups. A low prevalence of arrhythmias, other than sinus tachycardia, was also noted on ECGs and Holter recordings in previous studies of cardiac function in alcoholics during withdrawal, ${ }^{1415}$ and most of the arrhythmias disappeared within a few days. ${ }^{14}$

There are several earlier reports that mortality is higher in alcoholics with concomitant ischaemic heart disease than in non-alcoholics with ischaemic heart disease. ${ }^{16-18}$ Because sudden death especially is overrepresented among alcoholics with ischaemic heart disease, ${ }^{16-18}$ it seems reasonable to believe that lethal arrhythmias account for a part of the excess mortality.

In the present study, we intended to determine the specific effects of alcohol abuse and withdrawal on the cardiac rhythm. Therefore, we selected patients without clinical heart disease and without conditions known to be associated with heart disease. We recognised $c$ that absence of symptoms and signs of heart $\overrightarrow{\vec{F}}$ disease did not exclude the presence of $\frac{\sigma}{0}$ coronary artery disease or preclinical alcoholic cardiomyopathy. Nevertheless, we excluded क those patients with heart disease who were $\overparen{\otimes}$ most likely to develop arrhythmias during alcohol withdrawal.

The electrophysiological effects of long- ? term and short-term ethanol administration $\vec{\omega}$ have been studied in animals and humans. In a one year study Patterson et al infused ethanol selectively into the left circumflex coronary $N$ artery of dogs. ${ }^{19}$ Provocative ventricular pac- os ing was performed during anaesthesia with of intravenous sodium pentobarbital 48 hours after ethanol administration was stopped. This procedure produced ventricular tachycardia in 13 of 22 alcohol-treated dogs either $\stackrel{\oplus}{\circ}$ during baseline conditions or after administration of lignocaine or adrenaline, whereas pacing in six control animals that had received a long-term intracoronary saline infusion did $\vec{\ominus}$ not provoke ventricular tachycardia. In the same study, in vitro examinations disclosed that the resting membrane potential, the action potential amplitude, and the maximum rate of phase 0 depolarisation were lower in $\stackrel{0}{\circ}$ Purkinje cells from the alcohol-treated zone $\stackrel{\mathbb{Q}}{2}$ than in cells from the untreated part of the $\overrightarrow{0}$ myocardium. Patel and coworkers used a pro- $\exists$ grammable stimulation technique to induce ventricular fibrillation and measure ventricular fibrillation threshold (VFT) in dogs fed $\vec{\sigma}$ with ethanol for a year. They showed that the VFT was reduced in the alcohol treated dogs, $\frac{0}{7}$ and that the VFT was further reduced after short-term ethanol administration in the dogs fed ethanol but not in control animals. ${ }^{20}$

A study of non-alcoholic patients with vari- 윽 ous heart diseases, showed that acute admin- $\rightarrow$ istration of small amounts of alcohol delayed conduction at the atrial level, improved con- $\tilde{O}$ duction through the atrioventricular node, $N$ and shortened the effective refractory period $N$ of the ventricular myocardium. ${ }^{21}$ In another ${ }_{\sigma}^{\omega}$ experimental study of alcoholic patients with heart disease acute ethanol ingestion pro- $\frac{\text { C }}{\circ}$ longed the His-ventricular interval, and atrial $\stackrel{\oplus}{+}$ or ventricular tachyarrhythmias could be 0 induced by extrastimuli in 10 of the $14 \stackrel{\circ}{\circ}$ alcoholic patients. ${ }^{22}$

Thus it seems that long-term ingestion of $\stackrel{\mathbb{Q}}{\square}$ ethanol causes electrophysiological alterations in the heart which render the myocardium $ᄋ$ more sensitive to arrhythmogenic influences, and that previous alcohol abuse and the presence of heart diseases may affect the electrophysiological response to acute ingestion of ethanol.

In all but one of our patients, the blood ethanol concentration was zero when the 
Holter recording started, suggesting that we started the investigation too late in the withdrawal phase to detect any effect of alcohol intoxication on the heart rhythm. When Holter recordings were obtained during the phase of ethanol elimination in alcoholic men in a study at an acute detoxification centre arrhythmias such as atrial fibrillation and ventricular tachycardia were detected in some subjects. ${ }^{23}$ Arrhythmia was more common in those with known heart disease, and similar arrhythmias were detected in the same individuals after two weeks of sobriety. Thus it seems that pre-existing heart disease influences the capacity of ethanol ingestion to affect heart rhythm.

During alcohol withdrawal the activity of the central and peripheral adrenergic nervous system is increased ${ }^{5}$ as is the affinity of the $\beta$ adrenergic receptors for catecholamines. ${ }^{24}$ Many of the symptoms of alcohol withdrawal originate from this hyperadrenergic state, and treatment with propranolol suppresses alcohol withdrawal symptoms and reduces urinary excretion of noradrenaline. ${ }^{25}$ The increased adrenergic activity in many of our alcoholic patients accounted for their mean heart rate being about 30 beats/minute higher than in the control group. However, despite this neuroendocrine stimulation the diurnal variability of heart rate was preserved and resembled that of the controls, with a decrease at night.

During myocardial ischaemia, and especially in patients with acute myocardial infarction, high blood concentrations of catecholamines increase the risk of malignant arrhythmias and cardiac arrest. ${ }^{26}$ In our patients, who did not have ischaemic heart disease, the increased adrenergic stimulation might have prevented arrhythmias by raising the heart rate and thus making it more difficult for ectopic foci to elicit arrhythmias.

The role of the magnesium ion in the regulation of the intracellular electrolyte homoeostasis is crucial. ${ }^{27}$ It affects membrane stability and impulse generation in the heart and the nervous system. ${ }^{28}$ Magnesium deficiency is difficult to diagnose because normal serum concentrations of magnesium do not exclude magnesium depletion. ${ }^{29}$ Because the intravenous magnesium loading test was expected to detect depletion of body magnesium stores it was used in several clinical investigations. ${ }^{70-32}$ This method has the advantage of supplying depleted individuals with magnesium at the same time as they are tested. One problem is that it is difficult to ascertain whether the collection of urine is adequate. Furthermore, there is no general agreement about how magnesium deficiency should be defined. It has been claimed that a magnesium retention of more than $50 \%$ is consistent with severe deficiency and that magnesium deficiency is unlikely when the retention is less than $20 \% .{ }^{30}$ In healthy subjects used in studies as controls, less than $10 \%$ of magnesium was retained..$^{3132}$ In our study we used a retention of $30 \%$ as discriminator for magnesium depletion. Despite this rather high cut off, half of our patients were found to be magnesium depleted, thus verifying previous observations that magnesium deficiency is common in alcoholic people. ${ }^{67}$

Magnesium deficiency is often associated with hypokalaemia and there are reports of a strong correlation between the concentrations of magnesium and potassium in different tissues. ${ }^{334}$ On admission three of our patients had low serum potassium concentrations. The mean serum potassium concentration for the group had increased significantly after 48 hours, suggesting that the initial potassium concentrations might have been suboptimal in most of the patients. Hypokalaemia associated with magnesium deficiency commonly disappears after treatment with magnesium. ${ }^{2735}$ Serum concentrations of magnesium and potassium are also influenced by $\beta$ adrenergic stimulation, with a shift of these ions into the intracellular compartment. ${ }^{36}$ The magnesium infusion, the correction of alkalosis, and a gradual decline in $\beta$ adrenergic stimulation that was assumed to occur may all have been responsible for the increase in serum potassium and magnesium concentrations after admission to hospital.

The observed electrolyte disturbances were not accompanied by arrhythmias in our patients, but these changes might be more liable to induce malignant arrhythmias in alcoholic patients with ischaemic heart disease $^{3738}$ and preclinical alcoholic cardiomyopathy, and they may explain some of the excess mortality in sudden death described in these disorders. ${ }^{17} 39$

The prolongation of the QT interval predisposes to malignant ventricular arrhythmias ${ }^{40}$ and could account for some unexplained deaths in alcoholics: there are several case reports of an association between magnesium deficiency and QT prolongation. ${ }^{41} 42$ Alcoholic patients with liver cirrhosis had a longer $\mathrm{QT}_{c}$ interval than controls. ${ }^{43}$ Furthermore, those alcoholic patients who subsequently had sudden cardiac death had the longest $\mathrm{QT}_{\mathrm{c}}$ intervals. The alcoholic patients in this study had significantly lower serum magnesium concentrations than the controls, but there was no correlation between serum magnesium concentration and $\mathrm{QT}_{\mathrm{c}}$ interval. ${ }^{43}$ Despite the high frequency of magnesium deficiency in our study, none of our patients had $\mathrm{QT}_{\mathrm{c}}$ prolongation, and $\mathrm{QT}_{\mathrm{c}}$ was almost the same as in the healthy controls. This does not accord with the reported association between magnesium deficiency and $\mathrm{QT}_{\mathrm{c}}$ prolongation.

The medical treatment of withdrawal symptoms with chlomethiazole probably interfered with the aim of the study. This drug probably suppresses the withdrawal reaction by diminishing adrenergic activation, ${ }^{44}$ and it also prevents complications such as delirium tremens. ${ }^{45}$ In the central nervous system chlomethiazole enhances inhibitory GABAergic transmission, probably by acting on calcium-dependent chloride channels. ${ }^{46}$ This effect results in hyperpolarisation and increases the threshold for action potential generation in GABA-innervated neurons, 
which may account for the anticonvulsant action of chlomethiazole. ${ }^{46}$ The electrophysiological effects of chlomethiazole in myocardial cells or the conduction system of the heart are uncertain. Chlomethiazole may directly and indirectly decrease the risk of arrhythmias. Therefore, it seems appropriate to treat alcoholic patients with chlomethiazole during withdrawal. Additional treatment with $\beta$-adrenoceptor antagonist might diminish withdrawal symptoms, ${ }^{25}$ and magnesium supplementation can relieve symptoms of magnesium deficiency such as muscle weakness. ${ }^{47}$ In alcoholic patients with heart disease these treatments might provide additional protection against arrhythmias during withdrawal.

In conclusion, our investigation indicates that increased adrenergic activity, magnesium depletion, and to some extent hypokalaemia are common findings after heavy drinking in alcoholic men. However, despite these disturbances, which are often regarded as arrhythmogenic, no malignant arrhythmias were seen in patients without clinical heart disease during detoxification in hospital with chlomethiazole.

We thank Margareta Leijon for her help with the analyses of the Holter recordings and ECGs.

We thank the Göteborg Medical Society for financial support.

1 Petersson B, Krantz P, Kristensson H, Trell E, Sternby NH. Alcohol-related death: A major contributor to mortality in urban middle-aged men. Lancet 1982;ii: 1088-90.

2 Petersson B. Analysis of the role of alcohol in mortality, particularly sudden unwitnessed death, in middle-aged men in Malmö, Sweden. Alcohol Alcohol 1988;23: men in

3 Skullerud K, Andersen S Norheim, Olving JH. Alcohol and mortality statistics for 30-64 year-old men in Osloan autopsy study. Tidsskr Nor Laegeforen 1990;110: an autops

4 Clark JC. Sudden death in the chronic alcoholic. Forensic Sci Int 1988;36:105-11.

5 Pohorecky LA. Influence of alcohol on peripheral neurotransmitter function. Federation Proc 1982;41:2452-5.

$6 \mathrm{Lim}$ P, Jacob E. Magnesium status of alcoholic patients. Metabolism 1972;21:1045-51.

7 Bøhmer T, Mathisen B. Magnesium deficiency in chronic alcoholic patients uncovered by an intravenous loadin test. Scand $\mathcal{f}$ Clin Lab Invest 1982;42:633-6.

8 Iseri LT, Freed J, Bures AR. Magnesium deficiency and cardiac disorders. Am ₹ Med 1975;58:837-46.

9 Millane TA, Ward DE, Camm AJ. Is hypomagnesemia arrhythmogenic? Clin Cardiol 1992;15:103-8.

10 Gettes LS. Electrolyte abnormalities underlying lethal and ventricular arrhythmias. Circulation 1992;85(suppl 1): $70-6$.

11 Committee on Enzymes of the Scandinavian Society for Clinical Chemistry and Clinical Physiology. Recommended methods for the determination of four enzymes in blood. Scand f Clin Lab Invest 1974;33:291

12 Rose GA, Blackburn H, Gillum RF, Prineas RF Cardiovascular survey methods. Geneva: World Health Organization, 1982;124-42.

13 Hodges M, Salerno D, Erlien D. Bazett's QT correction reviewed: Evidence that a linear QT correction for heart rate is better. $¥ \mathrm{Am}$ Coll Cardiol 1983;1:694.

14 Ballas M, Zoneraich S, Yunis M, Zoneraich O, Rosner F Noninvasive cardiac evaluation in chronic alcoholic Noninvasive cardiac evaluation in chronic alcoholic patients with

15 Zilm DH, Jacob MS, MacLeod SM, Sellers EM, Ti TY. Propranolol and chlordiazepoxide effects on cardiac arrhythmias during alcohol withdrawal. Alcohol Clin Exp Res 1980;4:400-5.

16 Rosengren A, Wilhelmsen L, Pennert K, Berglund G, Elmfeldt D. Alcoholic intemperance, coronary heart disease and mortality in middle-aged Swedish men. Acta Med Scand 1987;222:201-13.

17 Lithell H, Áberg H, Selinus I, Hedstrand TH. Alcohol intemperance and sudden death. BMF 1987;294: 1456-8.
18 Wannamethee G, Shaper AG. Alcohol and sudden cardiac death. Br Heart $f$ 1992;68:443-8.

19 Patterson E, Dormer KJ, Scherlag BJ, Kosanke SD Schaper J, Lazzara R. Long-term intracoronary ethano administration. Electrophysiologic and morphologic administration. Electrophysio

20 Patel R, McArdle JJ, Regan TJ. Increased ventricula vulnerability in a chronic ethanol model despite reduced electrophysiologic responses to catecholamines. Alcohol Clin Exp Res 1991;15:785-9.

21 Gould L, Reddy CVR, Becker W, Oh KC, Kim SG. Electrophysiologic properties of alcohol in man F Electrocardiol 1978;11:219-26.

22 Greenspon AJ, Schaal SF. The "holiday heart": Electrophysiologic studies of alcohol effects in alcoholics. Ann Intern Med 1983;98:135-9.

23 Buckingham TA, Kennedy HL, Goenjian AK, Vasilomanolakis EC, Shriver KK, Sprague MK, Lyyski $D$. Cardiac arrhythmias in a population admitted to an acute alcoholic detoxification center. Am Heart $\mathcal{f} 1985$; acute alcoh

24 Banerjee SP, Sharma VK. Alterations in $\beta$-adrenergic receptor binding during ethanol withdrawal. Nature 1978;276:407-9.

25 Sellers EM, Degani NC, Zilm DH, Macleod SM Propranolol-decreased noradrenaline excretion and alcohol withdrawal. Lancet 1976;i:94-5.

26 Little RA, Frayn KN, Randell PE, Yates DW. Plasma catecholamines and cardiac arrest. Lancet 1985;ii:509-10.

27 Whang R, Whang DD, Ryan MP. Refractory potassium repletion. A consequence of magnesium deficiency. Arch repletion. A consequence of magnesium deficiency. Arch
Intern Med 1992;152:40-5.

28 Tso EL, Barish RA. Magnesium

Emerg Med 1992;10:735-45.

29 Reinhart RA. Magnesium metabolism. A review with special reference to the relationship between intracellular content and serum levels. Arch Intern Med 1988;148: 2415-20.

30 Ryzen E, Elbaum N, Singer FR, Rude RK. Parentera magnesium tolerance testing in the evaluation of magnesium deficiency. Magnesium 1985;4:137-47.

31 Rasmussen HS, McNair P, Gøransson L, Balsløv S, Graff Larsen O, Aurup P. Magnesium deficiency in patients with ischemic heart disease with and without acute myocardial infarction uncovered by an intravenous loading test. Arch Intern Med 1988;148:329-32.

32 Gullestad L, Dolva L, , Waage A, Falch D, Fagerthun H, Kjekshus J. Magnesium deficiency diagnosed by an intravenous loading test. Scand 7 Clin Lab Invest 1992 52:245-53.

33 Ralston MA, Murnane MR, Kelley RE, Altschuld RA, Unverferth DV, Leier CV. Magnesium content of serum, circulating mononuclear cells, skeletal muscle, and myocardium in congestive heart failure. Circulation 1989;80:573-80.

34 Reinhart RA, Broste SK, Spencer S, Marx Jr JJ, Haas RG, Rae $P$. Relation between magnesium and potassium concentrations in myocardium skeletal muscle, and mononuclear blood cells. Clin Chem 1992;38:2444-8.

35 Landahl S, Graffner C, Jagenburg R, Lundborg P, Steen B. Prevalence and treatment of hypomagnesemia in the elderly. Studies in a representative 70-year-old populaelderly. Studies in a representative Akt Gerontol 1980;10. tion and $397-402$.

36 Whyte KF, Addis GJ, Whitesmith R, Reid JL. Adrenergic control of plasma magnesium in man. Clin Sci 1987;72: 135-8.

37 Dyckner T. Serum magnesium in acute myocardial infarction. Acta Med Scand 1980;207:59-66.

38 Dyckner T, Helmers C, Lundman T, Wester PO. Initial serum potassium level in relation to early complications and prognosis in patients with acute myocardial infarction. Acta Med Scand 1975;197:207-10.

39 Vikert AM, Tsiplenkova VG, Cherpachenko NM. Alcoholic cardiomyopathy and sudden cardiac death. Alcoholic cardiomyopathy and

40 Alora A, Tijssen JGP, Roelandt JRTC, Pool J, Lubsen J. QTc prolongation measured by standard 12-lead electrocardiography is an independent risk factor for sudden trocardiography is an independent risk factor for sudden death due to cardiac arrest. Circulation 1991;83: 1888-94.

41 Topol EJ, Lerman BB. Hypomagnesemic torsades de pointes. Am ₹ Cardiol 1983;52:1367-8

42 Ramee SR, White CJ, Svinarich JT, Watson TD, Fox RF. Torsade de pointes and magnesium deficiency. $\mathrm{Am}$ Heart $\mathcal{~} 1985$; 109:164-7.

43 Day CP, James OFW, Butler TJ, Campbell RWF. QT prolongation and sudden cardiac death in patients with alcoholic liver disease. Lancet 1993;341:1423-28.

44 Brohult J, Levi L, Reichard $H$. Urinary excretion of $\frac{P}{\Phi}$ adrenal hormones in man. Effects of ethanol ingestion, $\unrhd$ and their modification by chlormethiazole. Acta Med $\sigma$ Scand 1970;188:5-13.

45 Majumdar SK. Chlormetiazole: Current status in the 8 treatment of the acute ethanol withdrawal syndrome. O treatment of the acute ethanol with
Drug Alcohol Depend 1991;27:201-7.

46 Ögren Alcohol Depend 1991;27:201-7. of action. Acta Psychiatr Scand 1986;73(suppl 329):13-27.

47 Gullestad L, Dolva LO, Söyland E, Manger AT, Falch D, Kjekshus J. Oral magnesium supplementation improves metabolic variables and muscle strength in alcoholics. Alcohol Clin Exp Res 1992;16:986-90.

\section{.}

.

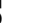

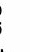

